\title{
Analisis Komparatif Kebijakan Perpajakan Atas Kegiatan Filantropi
}

\author{
Tri Maruli Sidabutar ${ }^{\mathrm{a}, *}$, P.M. John L. Hutagaol ${ }^{\mathrm{b}}$ and Jasman ${ }^{\mathrm{c}}$ \\ a Program Studi Akuntansi, Institut Keuangan Perbankan dan Informatika Asia \\ Perbanas, trimarulisidabutar@gmail.com, Indonesia \\ b Program Studi Akuntansi, Institut Keuangan Perbankan dan Informatika Asia \\ Perbanas,pmjhutagaol@gmail.com, Indonesia \\ c Program Studi Akuntansi, Institut Keuangan Perbankan dan Informatika Asia \\ Perbanas, jasman@perbanas.id, Indonesia
}

\begin{abstract}
This study aims to analyze tax exemption and tax deduction policies on philanthropic activities in Indonesia and some other countries as a basis of recommendation in improving taxation policies to encourage philanthropic activities in Indonesia. Comparative analysis was conducted towards the similar policies in 4 selected namely, the United States, Myanmar, Sri Lanka, and Malaysia. The data used in this study were obtained from the CAF World Giving Index 10th report, A Global Philanthropy Legal Environment Index, the World Bank List of economies 2019, and tax regulations from the selected countries. Data analysis was conducted through comparative analysis methods supported by primary data, namely the results of interviews and secondary data, namely the results of literature reviews. The results of the analysis show that the tax exemption and tax deduction policies for philanthropic activities in Indonesia are adequate. There are several tax exemption and tax deduction policies on philanthropic activities from the selected countries that can be used as a basis of recommendation and consideration in the formulation and improvement of the related tax policies in Indonesia.
\end{abstract}

Keywords: philanthropic activities, tax deduction, tax exemption, and tax incentives.

${ }^{*}$ Corresponding author. E-mail: trimarulisidabutar@gmail.com 


\section{Pendahuluan}

Secara etimologis istilah Filantropi (Philanthropy) berasal dari bahasa Yunani, Philos (berarti Cinta), dan Anthropos (berarti Manusia), sehingga secara harfiah, (Raditya, 2020) Filantropi adalah konseptualisasi dari praktek memberi (giving), pelayanan (services) dan asosiasi (association) secara sukarela untuk membantu pihak lain yang membutuhkan sebagai ekspresi rasa cinta. Filantropi dapat juga diartikan sebagai tindakan seseorang untuk mencintai sesama manusia serta nilai kemanusiaan, dengan cara menyumbangkan waktu, uang, dan tenaganya untuk menolong orang lain. Istilah ini umumnya diberikan kepada orang-orang yang memberikan dana untuk amal, sumbangan, dan bantuan.

Sejak awal mula perkembangan peradaban manusia, pada dasarnya kegiatan filantropi sudah ada. Terdapat beberapa faktor yang menggerakkan seseorang untuk melakukan kegiatan filantropi, diantaranya perilaku tanggung jawab moral untuk membantu sesama manusia, motivasi untuk mendapatkan kredibilitas atau pengakuan di mata masyarakat, dan perintah agama kepada para pemeluknya untuk melakukan kegiatan-kegiatan yang mencerminkan sifat filantropi.

Kegiatan filantropi belakangan ini terus meningkat dan memiliki peranan yang penting dalam pembangunan dan penyelesaian berbagai permasalahan sosial di Indonesia. Lembaga dunia yaitu Charities Aid Foundation (CAF) pada bulan Oktober 2018 (World Giving Index 2018) dalam laporannya, melaporkan telah melakukan survei tahunan yang dilakukan di lebih dari 140 negara yang secara bersama mewakili sekitar $95 \%$ populasi dewasa dunia (sekitar 5 miliar orang), dan diperoleh hasil Indonesia sebagai peringkat pertama negara paling dermawan. Tiga perilaku filantropi yang menjadi dasar survei yang dilakukan CAF (2018), diantaranya:

a. mendonasikan uang untuk kegiatan amal;

b. menolong orang asing;

c. menyediakan waktu untuk bekerja sosial atau sebagai sukarelawan.

Pada Oktober 2019, CAF dalam CAF World Giving Index 10th edition mengumumkan bahwa Indonesia menjadi peringkat ke-10 secara agregat dalam sepuluh tahun terakhir sebagai negara dengan skor tertinggi dalam indeks kebaikan dalam memberi (giving index).

Kegiatan filantropi merupakan kegiatan positif yang dapat membantu pemerintah dalam menyelesaikan permasalahan-permasalahan sosial yang terjadi di dalam masyarakat, oleh karena itu pemerintah perlu mendorong kegiatan ini. Berdasarkan survei yang telah dilakukan Nexus, Charities Aid Foundation dan McDermott Will \& Emery LLP dalam Rules to Give By Index terhadap 177 negara anggota Perserikatan Bangsa-Bangsa yang memiliki tax regime di negaranya. Diperoleh hasil 94,4\% (167 dari 177) negara memberikan insentif pajak berupa tax exemption terhadap non-profit organizations, $77,4 \%$ (137 dari 177) negara memberikan insentif pajak berupa tax deduction terhadap corporate yang melakukan donor, dan $66,1 \%$ (117 dari 177) negara memberikan insentif pajak berupa tax deduction terhadap individual yang melakukan donor. Survei ini menunjukan bahwa mayoritas negara-negara memberikan insentif pajak berupa tax exemption dan tax deduction untuk mendorong kegiatan filantropi.

Negara-negara mendorong masyarakat untuk melakukan kegiatan filantropi karena kesejahteraan sosial dan kepentingan publik tidak selalu dapat dipenuhi seluruhnya oleh pemerintah. Menurut Waluyo (2011), Pajak memiliki dua fungsi, yaitu berfungsi sebagai sumber dana yang diperuntukkan bagi pembiayaan pengeluaran-pengeluaran pemerintah (Budgeter - fungsi penerimaan) dan berfungsi sebagai alat untuk mengatur atau melaksanakan kebijakan di bidang sosial dan ekonomi (Regulator - fungsi mengatur).

Pemerintah Indonesia menjalankan fungsi regulator, yaitu mendorong masyarakat untuk melakukan kegiatan filantropi dengan mengatur dan melaksanakan kebijakan berupa pemberian insentif pajak. Pemberian insentif pajak tersebut telah diatur dalam Undang-Undang Nomor 7 Tahun 1983 tentang Pajak Penghasilan Sebagaimana Telah Beberapa Kali Diubah Terakhir dengan UU Nomor 36 Tahun 2008 (UU PPh), Insentif pajak diberikan baik dari sisi penerima bantuan, yaitu sumbangan sebagai pengecualian dari objek pajak (tax exemption), dan dari sisi pemberi bantuan, yaitu sumbangan sebagai biaya yang dapat dikurangkan dari penghasilan bruto (tax deduction).

Berdasarkan kondisi bahwa saat ini mayoritas negara-negara termasuk Indonesia menggunakan kebijakan insentif pajak berupa tax exemption dan tax deduction sebagai pendorong kegiatan filantropi, maka penulis tertarik untuk melakukan penelitian yang membahas tentang "Analisis Komparatif Kebijakan Perpajakan atas Kegiatan Filantropi" dengan tujuan untuk mengetahui kebijakan Tax Exemption dan Tax Deduction dari negara pembanding yang dapat dijadikan masukan untuk 
penyempurnaan kebijakan perpajakan dalam rangka mendorong kegiatan filantropi di Indonesia.

\section{Kajian Teoris}

\section{The Four Cannons Maxim Taxation}

Adam smith (1723-1790) dalam bukunya an inquiry into the nature and causes of the wealth of nations (terkenal dengan nama wealth of nations) mengemukakan empat asas pemungutan pajak yang lazim disebut "the four cannons maxims taxation". Suatu aturan hukum tentang pajak yang adil harus memenuhi syarat:

1. Equality and Equity

2. Certainty

3. Convenient of Payment

4. Economic of Collection

\section{General Taxation Principal}

OECD (2014) mengemukakan terdapat lima prinsip umum dalam pemungutan pajak, yaitu.

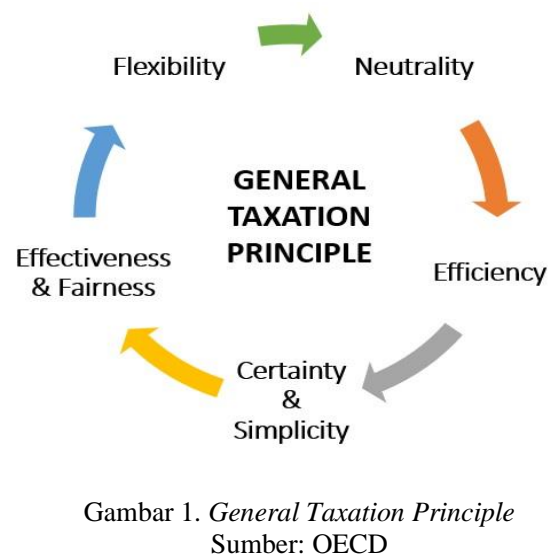

\section{Taxpayer's Behavioral Responses}

Theory of Planned Behavior (TPB) yang dikemukakan oleh Ajzen (1985) adalah teori psikologi sosial yang mengkaitkan behavioral belief, normative belief, dan control belief untuk memprediksi intensi dan perilaku individu. Dikaitkan dengan konteks perumusan skema insentif perpajakan, model $T P B$ menangkap faktor motivasi individu yang mendorong perilaku seorang individu. Insentif perpajakan dan skema fair tax system akan mendorong attitude, dan subjective norm yang akan mendorong intens Wajib
Pajak dan mengubah perilaku Wajib Pajak secara keseluruhan.

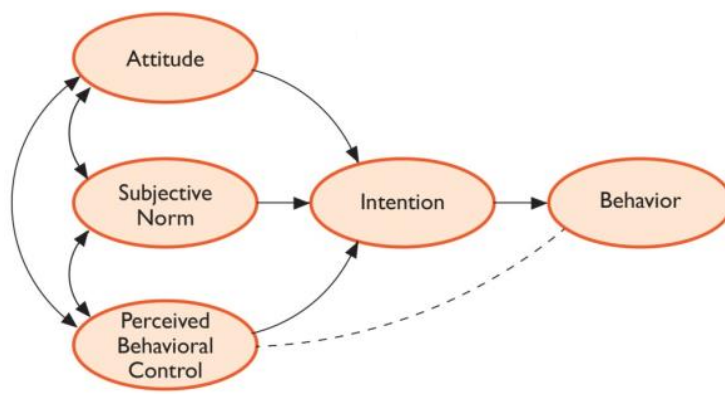

Gambar 2. Theory of Planned Behavior Sumber: Ajzen (1985)

\section{Total Cost of Taxation}

Ruang lingkup insentif pajak bagi kegiatan filantropi sangat luas. Salah satu konsep dalam pemberian fasilitas perpajakan adalah kemudahan layanan dan simplifikasi aturan dengan tujuan untuk memperkecil compliance cost bagi subjek pajak yang menjadi sasaran kebijakan fiskal. Pertimbangan pemerintah lainnya dalam perumusan kebijakan di bidang perpajakan adalah terkait dengan prinsip economic of collection, dalam konteks ini pajak harus dipungut dengan biaya administrasi yang paling efisien.

\section{Insentif Pajak}

Garner (2004) dalam Black Law Dictionary menjelaskan Insentif Pajak adalah "A governmental enticement, through a tax benefit, to engage in a particular activity, such as the contribution of money or property to qualified charity".

\section{Metode Penelitian}

Penelitian ini adalah penelitian kualitatif dengan menggunakan sumber data berupa data primer dan data sekunder. Data primer diperoleh dari hasil wawancara terhadap pejabat dari Direktorat Jenderal Pajak yang memiliki memiliki dalam perumusan kebijakan di bidang perpajakan.

Tabel 1

Narasumber Wawancara

\begin{tabular}{llllll}
\hline No & Nama & Jabatan & & Unit Kerja & \\
\hline 1 & Safatul & Kepala Seksi Peraturan & Direktorat & \\
& & PPh Badan II, dan & Peraturan & \\
& & Anggota & Tim & Perpajakan & II,
\end{tabular}




\begin{tabular}{|c|c|c|c|}
\hline No & Nama & Jabatan & Unit Kerja \\
\hline \multirow{5}{*}{2} & \multirow{5}{*}{ Fuad } & $\begin{array}{l}\text { Penyusun PMK Nomor } \\
90 \text { Tahun } 2020\end{array}$ & $\begin{array}{l}\text { Direktorat } \\
\text { Jenderal Paiak }\end{array}$ \\
\hline & & Pelaksana Peraturan & Direktorat \\
\hline & & PPh Badan II, dan & Peraturan \\
\hline & & Anggota $\quad$ Tim & Perpajakan \\
\hline & & $\begin{array}{l}\text { Penyusun PMK Nomor } \\
90 \text { Tahun } 2020\end{array}$ & $\begin{array}{l}\text { Direktorat } \\
\text { Jenderal Pajak }\end{array}$ \\
\hline
\end{tabular}

Sedangkan data sekunder diperoleh dari telaah literatur terhadap bahan bacaan terkait, berita dari media masa online, peraturan perpajakan Indonesia dan negara-negara pembanding, dan sumber analisis lainnya.

\section{Sampling}

Peneliti menggunakan data dari hasil survei yang telah dilakukan oleh Nexus, Charities Aid Foundation dan McDermott Will \& Emery LLP dalam Rules to Give By Index terhadap 177 negara anggota Perserikatan Bangsa-Bangsa yang memiliki tax regime di negaranya, sebagai populasi penelitian. Agar penelitian ini memberikan pemahaman yang sesuai dan tidak menyimpang dari apa yang diharapkan, maka peneliti melakukan sampling terhadap populasi negara untuk mengetahui kebijakan Tax Exemption dan Tax Deduction negara lain yang dapat dijadikan masukan untuk penyempurnaan kebijakan perpajakan dalam rangka mendorong kegiatan filantropi di Indonesia. Sampling penelitian dilakukan dengan pemilihan negara berdasarkan kriteria sampling yang ditentukan oleh peneliti, yaitu negara yang memiliki kebijakan insentif pajak dalam bentuk Tax Exemption dan Tax Deduction terkait kegiatan filantropi, dan negara dengan peringkat filantropi tertinggi, atau belokasi pada region yang sama dengan Indonesia, atau memiliki pendapatan per kapita yang sama dengan Indonesia. Adapun pemilihan sampling dijelaskan dalam Lampiran 1 .

\section{Metode Pengolahan dan Analisis Data}

Peneliti melakukan pengolahan dan analisis data dengan tahapan sebagai berikut:

1. mendeskripsikan data (describing);

2. melakukan klasifikasi (classifying);

3. membangun hubungan-hubungan (connecting);

4. menghasilkan kesimpulan.

Dengan data-data yang telah diperoleh tersebut kemudian peneliti melakukan komparasi terhadap data negara Indonesia dan negara pembanding.

\section{Temuan dan Pembahasan}

Sebagaimana telah diuraiakan pada bagian sebelumnya, dalam konteks stimulus terhadap kegiatan filantropi, mayoritas negara-negara di dunia memberikan kebijakan insentif pajak berupa tax exemption dan tax deduction. Dengan skema insentif berarti pemerintah menyerahkan keputusan kepada pihak-pihak yang terkait dalam kegiatan filantropi tersebut untuk berkontribusi secara langsung terhadap sektor-sektor yang ingin mereka danai.

Dari sudut pandang lain, terdapat risiko penyelewengan atas insentif pajak terhadap kegiatan filantropi, yaitu penyelewengan untuk memperoleh keuntungan pajak serta keuntungan finansial dari tax evasion dan money-laundering. OECD (2009) mengungkapkan bukti di mana kegiatan amal dan filantropi memiliki kecenderungan untuk digunakan sebagai instrumen penghindaran pajak dan pencucian uang. Kasus yang sering terjadi adalah kasus yang terstruktur dan tidak individual. Pada umumnya, dalam hal terjadi tindak pidana di bidang perpajakan berupa penggelapan pajak, skema pencucian uang akan digunakan untuk menyembunyikan hasil dari penggelapan pajak tersebut. OECD (2009) merekomendasikan penggunaan instrumen IT sebagai alat deteksi kecurangan pajak terkait filantropi, mengingat praktik-praktik yang digunakan oleh pelaku penggelapan pajak semakin kompleks.

\section{Kebijakan Tax Exemption dan Tax Deduction atas kegiatan filantropi di Indonesia}

Pemberian insentif pajak untuk kegiatan filantropi telah diatur dalam Undang-Undang Nomor 7 Tahun 1983 tentang Pajak Penghasilan Sebagaimana Telah Beberapa Kali Diubah Terakhir dengan UU Nomor 36 Tahun 2008 (UU PPh), Insentif pajak diberikan baik dari sisi penerima bantuan, yaitu sumbangan sebagai pengecualian dari objek pajak (tax exemption), dan dari sisi pemberi bantuan, yaitu sumbangan sebagai biaya yang dapat dikurangkan dari penghasilan bruto (tax deduction).

Insentif dalam bentuk tax exemption atau pengecualian objek pajak bagi penerima bantuan atau organisasi filantropi di Indonesia diatur dalam UU PPh Pasal 4 ayat (3) huruf a dan huruf $m$. Terdapat tiga pengecualian objek pajak yang berkaitan dengan kegiatan filantropi:

1. Bantuan atau sumbangan, termasuk zakat yang diterima oleh badan amil zakat atau lembaga amil zakat yang dibentuk atau disahkan oleh 
pemerintah dan yang diterima oleh penerima zakat yang berhak atau sumbangan keagamaan yang sifatnya wajib bagi pemeluk agama yang diakui di Indonesia, yang diterima oleh lembaga keagamaan yang dibentuk atau disahkan oleh pemerintah dan yang diterima oleh penerima sumbangan yang berhak, yang ketentuannya diatur dengan atau berdasarkan Peraturan Pemerintah;

2. Harta hibahan yang diterima oleh keluarga sedarah dalam garis keturunan lurus satu derajat, badan keagamaan, badan pendidikan, badan sosial termasuk yayasan, koperasi, atau orang pribadi yang menjalankan usaha mikro dan kecil, yang ketentuannya diatur dengan atau berdasarkan Peraturan Menteri Keuangan; dan

3. Sisa lebih yang diterima atau diperoleh badan atau lembaga nirlaba yang bergerak dalam bidang pendidikan dan/atau bidang penelitian dan pengembangan, yang telah terdaftar pada instansi yang membidanginya, yang ditanamkan kembali dalam bentuk sarana dan prasarana kegiatan pendidikan dan/atau penelitian dan pengembangan, dalam jangka waktu paling lama 4 (empat) tahun sejak diperolehnya sisa lebih tersebut, yang ketentuannya diatur lebih lanjut dengan atau berdasarkan Peraturan Menteri Keuangan.

Sedangkan insentif pajak dalam bentuk tax deduction atau biaya yang dapat dikurangkan dari penghasilan bruto bagi pemberi sumbangan di Indonesia telah diatur dalam UU PPh Pasal 6 ayat (1) huruf $i, j, k, 1$, dan $m$. Terdapat lima jenis sumbangan yang dapat dikurangkan dari penghasilan bruto:

1. sumbangan dalam rangka penanggulangan bencana nasional yang ketentuannya diatur dengan Peraturan Pemerintah;

2. sumbangan dalam rangka penelitian dan pengembangan yang dilakukan di Indonesia yang ketentuannya diatur dengan Peraturan Pemerintah;

3. biaya pembangunan infrastruktur sosial yang ketentuannya diatur dengan Peraturan Pemerintah;

4. sumbangan fasilitas pendidikan yang ketentuannya diatur dengan Peraturan Pemerintah; dan

5. sumbangan dalam rangka pembinaan olahraga yang ketentuannya diatur dengan Peraturan Pemerintah.

Dalam Peraturan Pemerintah No. 93 Tahun 2010 diatur bahwa sumbangan yang dapat dikurangkan dari penghasilan bruto untuk 1 (satu) tahun dibatasi tidak melebihi 5\% dari penghasilan neto fiskal Tahun Pajak sebelumnya.

Terdapat kewajiban melakukan pelaporan bagi pihak/lembaga penerima sumbangan kepada Direktur Jenderal Pajak sebagaimana diatur dalam Peraturan Menteri Keuangan (PMK) Nomor 76 Tahun 2011. selain itu Wajib Pajak pemberi sumbangan juga memilki kewajiban untuk melampirkan bukti penerimaan sumbangan menurut PMK ini.

\section{Kebijakan Tax Exemption dan Tax Deduction atas kegiatan filantropi di Amerika Serikat}

Insentif perpajakan atas kegiatan filantropi di Amerika Serikat diberikan berupa tax exemption bagi organisasi filantropi dan tax deduction bagi donatur. Untuk mendapatkan insentif berupa tax exemption, maka setiap organisasi filantropi harus memenuhi persyaratan organization test dan operational test. Terdapat kategori khusus bagi penerima tax exemption, yaitu organisasi yang memiliki tujuan khusus untuk amal atau biasa disebut dengan charitable organization. Terminologi amal sendiri dibagi kedalam empat kategori, yaitu:

a. dalam rangka pengurangan kemiskinan;

b. dalam rangka peningkatan pendidikan;

c. dalam rangka peningkatan keagamaan;dan

d. memberikan manfaat bagi komunitas.

Secara umum, organisasi yang bebas pajak harus mengajukan melaporkan annual information return (Formulir 990 (PDF) atau Formulir 990-EZ (PDF)). Sebagian besar organisasi kecil bebas pajak yang penerimaan bruto tahunannya $\$ 50.000$ atau kurang dapat memenuhi persyaratan pelaporan tahunan dengan menggunakan Formulir 990-N secara elektronik jika mereka memilih untuk tidak mengajukan Formulir 990 atau Formulir 990-EZ. Terdapat beberapa organisasi yang dikecualikan dari pelaporan annual information return : organisasi keagamaan/gereja; lembaga negara; korporasi tertentu yang diorganisir oleh Undang-Undang Kongres; unit pemerintah atau afiliasi dari unit pemerintah; yayasan swasta (yayasan swasta diharuskan untuk setiap tahun mengajukan Formulir 990-PF, Return of Private Foundation); dan organisasi politik.

Tax deduction diberikan kepada orang pribadi maupun badan usaha, dengan ketentuan sebagai berikut:

a. Untuk orang pribadi besarnya nilai sumbangan tidak melebihi $50 \%$ dari pendapatan bruto pertahunnya, dan apabila sumbangan diberikan 
bukan dalam bentuk uang maka batasan nilai sumbangan sebesar $30 \%$.

b. Untuk badan besarnya nilai sumbangan tidak melebihi $10 \%$ dari penyesuaian pendapatan bruto pertahunnya.

\section{Kebijakan Tax Exemption dan Tax Deduction atas kegiatan filantropi di Myanmar}

Sama halnya seperti di Amerika Serikat, insentif perpajakan atas kegiatan filantropi di Myanmar berupa tax exemption dan tax deduction. Tax exemption, diberikan bagi lembaga amal atau keagamaan dan yang diterapkan semata-mata untuk tujuan keagamaan / amal dikecualikan dari pajak penghasilan.

Secara umum pelaporan pajak dilakukan dalam waktu tiga bulan sejak akhir tahun pajak untuk tahun pajak yang akan dilaporkan. Dengan adanya pembebasan organisasi nirlaba dari pajak penghasilan, maka kewajiban pelaporan ini tidak berlaku untuk mereka.

Pemberian insetif perpajakan berupa tax deduction diberikan hingga 25 persen dari total pendapatan bersih untuk sumbangan kepada lembaga keagamaan atau lembaga amal apapun yang diakui oleh Kementerian Keuangan dan Pendapatan dengan pemberitahuan. Kontribusi untuk amal didefinisikan dalam Undang-undang Pajak Penghasilan Myanmar (1974) sebagai "kontribusi untuk kepentingan publik seperti sumbangan untuk pendidikan, kesehatan dan kesejahteraan orang miskin".

\section{Kebijakan Tax Exemption dan Tax Deduction atas kegiatan filantropi di Sri Lanka}

Di Negara Sri Lanka dikenakan pajak sebesar 3\% atas uang yang diterima organisasi filantropi pada suatu tahun pajak yang berupa hibah, donasi kontribusi ataupun bentuk lainnya, sebagai laba yang akan dikenakan pajak (kewajiban selain pajak yang terutang atas penghasilan lainnya). Namun demikian Komisaris Jenderal berwenang untuk memberikan pembebasan pajak atas penghasilan dari amal bila penggunaannya sesuai dengan area yang disetujui. Selain itu, organisasi filantropi diberikan diskon untuk pemotongan pajak atas bunga yang dibayarkan oleh bank atau lembaga keuangan lainnya.

Organisasi filantropi memiliki kewajiban pelaporan tahunan dan penyampaian pernyataan triwulanan untuk menjelaskan dana yang diterima dan kegiatan yang dilakukan. Selain itu juga menyampaikan aplikasi permohonan remisi bila kegiatan sesuai dengan kegiatan yang memungkinkan mendapatkan remisi pembayaran pajak penghasilan.

Sedangkan pemberian insentif berupa tax deduction diberikan kepada badan dan orang pribadi dengan batasan sebagai berikut.

a. Untuk orang pribadi sampai dengan sepertiga penghasilan atau Rupees 75.000, mana yang lebih rendah.

b. Untuk badan maksimal $20 \%$ dari penghasilan atau Rupees 500.000, mana yang lebih rendah.

\section{Kebijakan Tax Exemption dan Tax Deduction atas kegiatan filantropi di Malaysia}

Insentif perpajakan yang diberikan Negara Malaysia berupa tax exemption diberikan kepada NonGovernment Organizations (NGO) yang telah mengajukan diri dan disetujui oleh IRB sebagai Charitable Corporations sehingga memiliki nomor ijin untuk menerima tax exemption. Sebagai charitable corporations, NGO tetap memiliki kewajiban pelaporan dikarenakan Malaysia merupakan negara self-assesment.

Donasi yang diberikan kepada charitable corporations mendapatkan insentif berupa tax deduction maksimal 7 persen dari penghasilan. Tax Deduction tak dibatasi dalam hal donasi diberikan kepada pemerintah, negara bagian, dan museum. Sedangkan donasi kepada fasilitas kesehatan dan perpustakaan berupa uang dan fasilitas dibatasi tidak melebihi 20.000 ringgit.

\section{Pembahasan Penelitian}

Pemberian insentif pajak berupa tax exemption dan tax deduction diharapkan dapat menjadi faktor motivasi seseorang (Wajib Pajak Badan dan Orang Pribadi) untuk melakukan kegiatan filantropi. Sebagaimana dijelaskan dalam Theory of Planned Behavior (TPB), insentif perpajakan dan skema fair tax system dipercaya akan mendorong attitude, dan subjective norm yang kemudian mendorong intens Wajib Pajak dan mengubah perilaku Wajib Pajak. Tetapi tidak dapat dipungkiri bahwa pemberian insentif yang bercelah memberi peluang kepada Wajib Pajak untuk melakukan tax evasion dan money laundering (OECD, 2009)

Sebagaimana telah dibahas dan didiskusikan bersama dengan narasumber wawancara penelitian, terdapat beberapa perbedaan dalam pengaturan tax exemption dan tax deduction atas kegiatan filantropi 
antara Indonesia dan negara pembanding. Beberapa hal yang dapat dijadikan masukan untuk penyempurnaan kebijakan perpajakan dalam rangka mendorong kegiatan filantropi di Indonesia.:

1. Pelaksanaan organizational test dan operational test di Indonesia telah dilakukan oleh lembaga/instansi lain diluar institusi pajak. Mengingat pemberian tax exemption akan menambah tax expenditures, peneliti berpendapat perlu dipertimbangkan untuk mengikutsertakan Direktorat Jenderal Pajak dalam proses pelaksanaan test tersebut.

2. Pelaporan dalam PMK Nomor 76 Tahun 2011 adalah pelaporan dalam konteks perpajakan. Mengingat salah satu konsep dalam pemberian fasilitas perpajakan adalah kemudahan layanan dan simplifikasi aturan dengan tujuan salah satunya untuk memperkecil compliance cost bagi subjek pajak yang menjadi sasaran kebijakan fiskal, peneliti berpendapat agar dipertimbangkan untuk memberikan kemudahan dalam kewajiban pelaporan penerimaan dan penyaluran sumbangan, misalnya dengan pelaporan secara online. Pelaporan secara online ini akan bermanfaat baik bagi Wajib Pajak untuk kemudahan pemenuhan kewajiban maupun Direktorat Jenderal Pajak untuk kemudahan dalam pengawasan.

3. Batasan nilai sumbangan yang dapat dikurangkan dari penghasilan bruto dan dasar penghitungannya sangat tergantung pada karakteristik dan struktur pendapatan pada suatu negara. Tugas utama mensehjahterakan masyarakat adalah tugas negara, maka pembatasan tersebut diperlukan. Sedangkan batasan ini adalah bentuk mitigasi terhadap perusahaan agar tidak memanfaatkan insentif untuk penghindaran pajak. Dengan demikian, peneliti berpendapat bahwa fokus dari batasan nilai sumbangan yang dapat dikurangkan dari penghasilan bruto adalah pengawasan terhadap Wajib Pajak agar tidak memanfaatkan fasilitas untuk melakukan tindak penghindaran pajak.

4. Pengecualian objek pajak PPh yang diberikan kepada orang pribadi UMKM dalam konteks kegiatan filantropi adalah bentuk keberpihakan pemerintah untuk mendorong UMKM. Peneliti berpendapat pemanfaatan fungsi lembaga filantropi sebagai penyalur bantuan terhadap seluruh pihak yang membutuhkan (termasuk mendorong UMKM) dapat dipertimbangkan sebagai skema yang lebih baik dalam upaya pencegahan terjadinya tindak penghindaran pajak, karena akan lebih mudah dalam pengawasannya.

\section{Kesimpulan dan Saran}

\section{Kesimpulan}

Beberapa negara di dunia seperti Amerika Serikat, Myanmar, Sri Lanka, dan Malaysia menerapkan insentif pajak berupa tax deduction sebagai pengurang penghasilan kena pajak dan tax exemption berupa pengecualian sumbangan sebagai objek pajak, untuk kegiatan filantropi. Terdapat beberapa perbedaan bentuk pengaturan dari tax deduction dan tax exemption keempat negara pembanding tersebut bila dibandingkan dengan Indonesia. Perbedaan tersebut diantaranya: Penentuan lembaga filantropi penerima fasilitas tax exemption melalui proses organizational test dan operational test; kewajiban pelaporan bagi lembaga filantropi secara online; batasan nilai sumbangan yang dapat dikurangkan dari penghasilan (tax deduction); dan subjek pajak penerima fasilitas tax exemption. Perbedaan-perbedaan bentuk pengaturan tax exemption dan tax deduction tersebut dapat digunakan Indonesia sebagai bahan kajian dan pertimbangan juga masukan untuk penyempurnaan kebijakan perpajakan dalam rangka mendorong kegiatan filantropi di Indonesia.

\section{Saran}

Penelitian selanjutnya diharapkan dapat menambah jumlah negara pembanding yang dikomparasi, baik menggunakan kriteria sample yang sama maupun dengan melakukan perluasan kriteria, dengan penambahan ini diharapkan dapat memperbanyak masukan untuk penyempurnaan kebijakan perpajakan dalam rangka mendorong kegiatan filantropi di Indonesia.

\section{Daftar Pustaka}

Charities Aid Foundation. (2019). CAF World Giving Index 10th Edition. Diperoleh dari www.cafonline.org

Charities Aid Foundation. (2018). CAF World Giving Index 2018 Diperoleh dari www.cafonline.org

Department of the Treasury Internal Revenue Service. (2020). Instructions for Form 990 Return of Organization. Diperoleh dari https://www.irs.gov/pub/irs-pdf/i990.pdf

Department of The Treasury Internal Revenue Service. (2020). Publication 526 Cat. No. 15050A Charitable Contributions. Diperoleh dari https://www.irs.gov/pub/irs-pdf/p526.pdf 
Garner, B. A. (2004). Black Law Dictionaray (Eight). USA: Thomson West.

Government of The Republic of The Union of Myanmar. (2011). Myanmar Income-Tax Law (As amended up to November 2011) November 2011. Diperoleh dari https://www.dica.gov.mm/sites/dica.gov.mm/files/document-

files/income_tax_law_amended_2011_eng.pdf

Inland Revenue Board of Malaysia. (2019). Act 53 INCOME TAX ACT $1967 . \quad$ Diperoleh dari http://www.hasil.gov.my/bt_goindex.php?bt_kump=5\&bt_skum=5 \&bt_posi $=3 \& b t \_u n i t=1 \& b t \_s e q u=2 \& b t \_l g v=2$

Julius Kuhl, J. B. (1985). Action Cognition to Behavior (1st edition). https://doi.org/10.1007/978-3-642-69746-3

Nexus, McDermott Will \& Emery, C. A. F. (2014). Rules to Give By. Diperoleh dari https://www.cafonline.org/aboutus/publications/2014-publications/rules-to-give-by

Organisation For Economic Co-Operation and Development. (2009). Report on Abuse of Charities for Money-Laundering and Tax Evasion. Diperoleh dari https://www.oecd.org/tax/exchangeof-tax-information/42232037.pdf

Organisation for Economic Co-Operation and Development. (2014). Addressing the Tax Challenges of the Digital Economy. Diperoleh dari https://www.oecd.org/tax/addressing-the-taxchallenges-of-the-digital-economy-9789264218789-en.htm

Parliament of The Democratic Socialist Republic of Sri Lanka. (2017). Inland Revenue Act, No. 24 of 2017.

Parliament of The Democratic Socialist Republic of Sri Lanka. (2015). Inland Revenue Act, No. 10 of 2006.
Parliament of The Democratic Socialist Republic of Sri Lanka (2017). Manual of Inland Revenue Act. Diperoleh dari http://www.ird.gov.lk/en/publications/Acts_Income

Tax_2017/Guide to Inland Revenue Act.pdf

Pemerintah Indonesia. (2008). Undang-Undang Republik Indonesia Nomor 7 Tahun 1983 Tentang Pajak Penghasilan Sebagaimana Telah Beberapa Kali Diubah Terakhir Dengan Undang-undang Republik Indonesia Nomor 36 Tahun 2008.

Pemerintah Indonesia. (2011). Peraturan Menteri Keuangan Republik Indonesia Nomor 76/PMK.03/2011 Tentang Tata Cara Pencatatan Dan Pelaporan Sumbangan Penanggulangan Bencana Nasional, Sumbangan Penelitian Dan Pengembangan, Sumbangan Fasilitas Pendidikan, Sumbangan Pembinaan Olahraga, Dan Biaya Pembangunan Infrastruktur Sosial Yang Dapat Dikurangkan Dari Penghasilan Bruto.

Pemerintah Indonesia. (2010). Peraturan Pemerintah Republik Indonesia Nomor 93 Tahun 2010 Tentang Sumbangan Penanggulangan Bencana Nasional, Sumbangan Penelitian Dan Pengembangan, Sumbangan Fasilitas Pendidikan, Sumbangan Pembinaan Olahraga, Dan Biaya Pembangunan Infrastruktur Sosial

Raditya, D. (2020). Mengenal Filantropi Sosial - Creative HUB Fisipol UGM. Diperoleh dari https://chub.fisipol.ugm.ac.id/2020/02/03/mengenal-filantropisosial/

Smith, A. (2007). An Inquiry into The Nature and Causes of The Wealth of Nations. Diperoleh dari Https://Www.Ibiblio.Org/M1/Libri/S/Smitha_Wealthnations_P.Pdf Waluyo. (2011). Perpajakan Indonesia. Jakarta: Salemba Empat. 


\section{Lampiran 1}

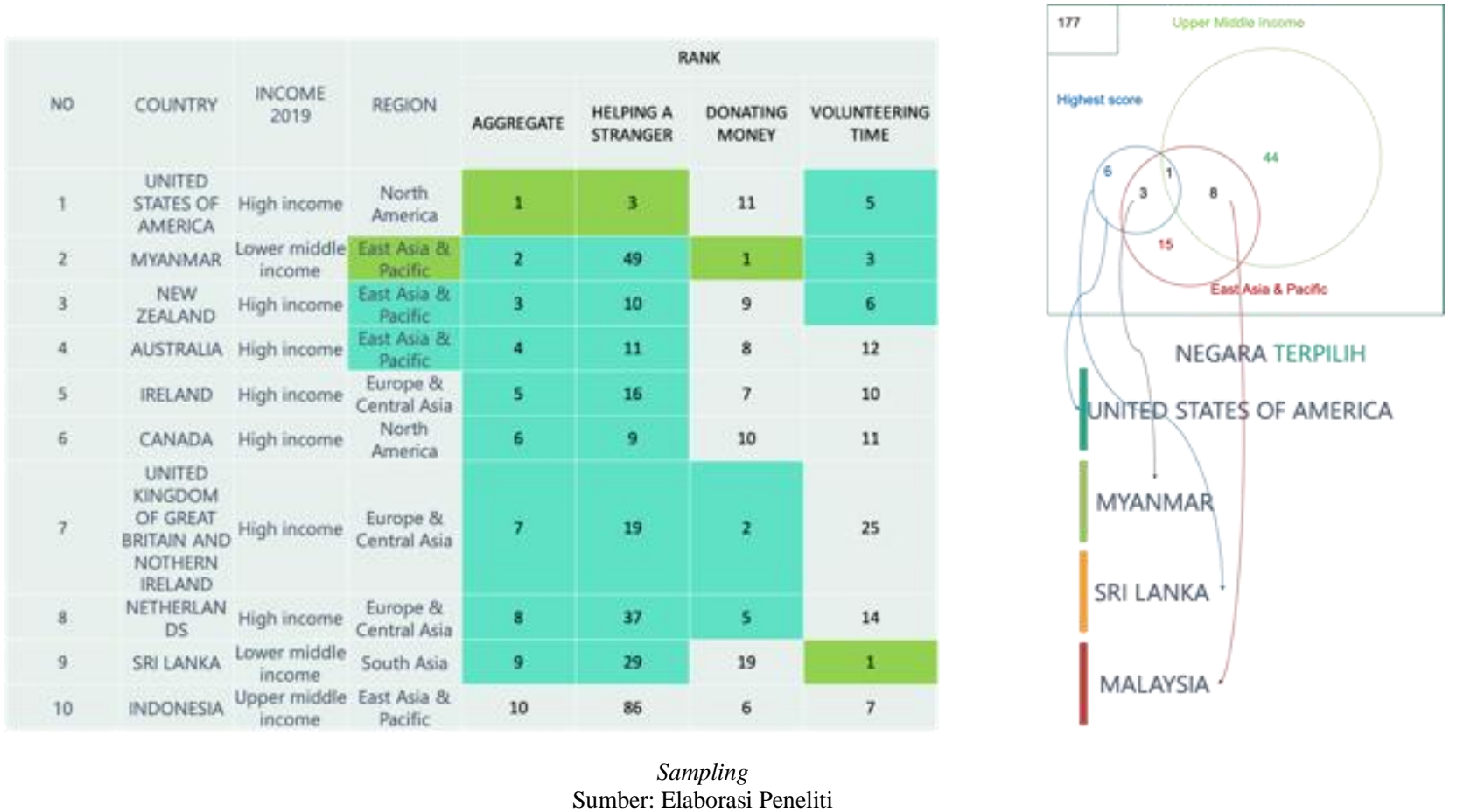

\section{Lampiran 2}

Dasar Hukum Kebijakan Tax Exemption dan Tax Deduction atas kegiatan filantropi di Indonesia dan negara pembanding

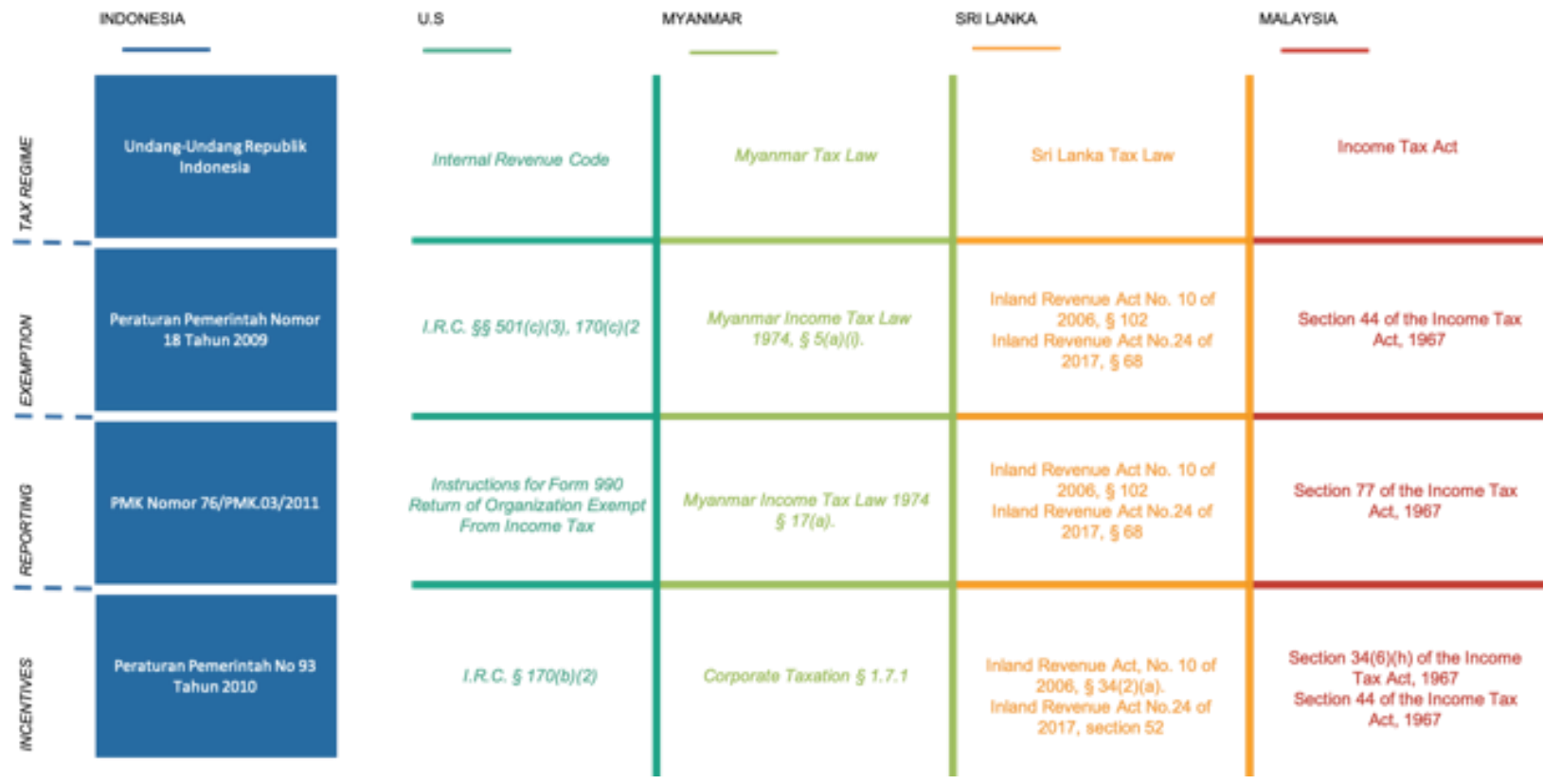

Sumber: Elaborasi Peneliti 


\section{Lampiran 3}

Kebijakan Tax Exemption dan Tax Deduction atas Kegiatan Filantropi di Indonesia dan Negara Pembanding

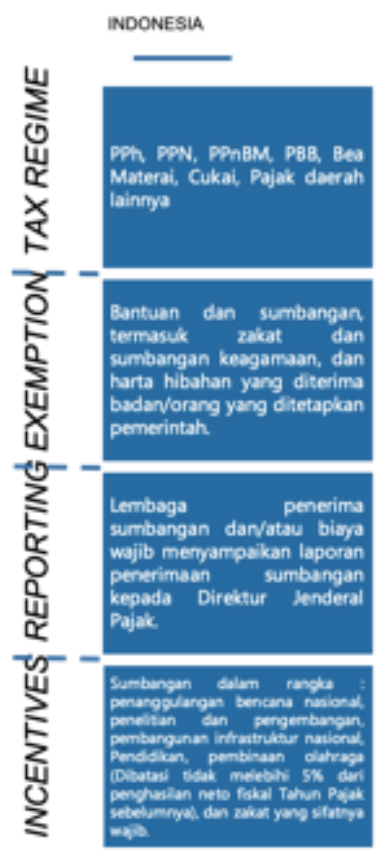

u.s
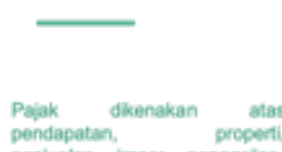

pentualan, impor, pangagian,

perkebunan, dan hadiah

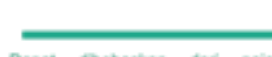

Dapal deobaskan dat pajak

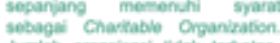
Jumlah organisas bidak terbatas, setapi menghurusean organiast dogerasikan

menguntungear

pengendali organisasi

Oiwajbian melakikan pelapocan paiak doeminir 900 , Roum Taxil). Menggunakia formule 900 EZ dalam hal perghasilan brite sso nog atay hurang Perpeoullag pelapcran untuk

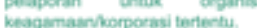

Kontribusi berupa uang properti daniasau jasa layanar yang dberkan kepada Ovalined tax-exump Organization hing son Organcaban, Hngsa sow car pondopatan ketor. dan 30 . untuk indiwidual. Hingga $10 \%$
MYANMAR

\begin{tabular}{|c|c|c|}
\hline $\begin{array}{l}\text { Pajak dikenakan atas } \\
\text { penghasilan, pajak komersial, } \\
\text { den Bea Materai }\end{array}$ & 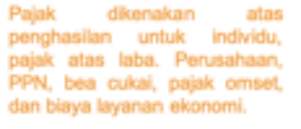 & $\begin{array}{l}\text { Pajak dikenakan atas } \\
\text { pendapatan dan properti rill. } \\
\text { Tidak ada pajak warisan. }\end{array}$ \\
\hline 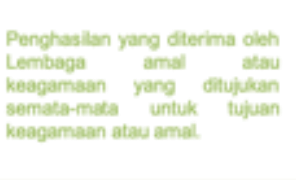 & 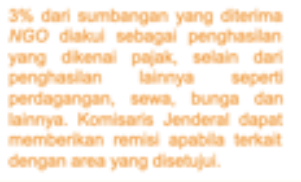 & $\begin{array}{l}\text { NGO yang telah mengajukan } \\
\text { dri sebagai charitablo } \\
\text { corporations dan disetujui oleh } \\
\text { IRB akan mendapat nomor in } \\
\text { untuk menerima tax } \\
\text { exemptions. }\end{array}$ \\
\hline 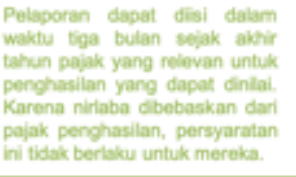 & 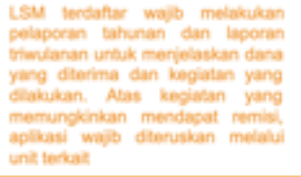 & $\begin{array}{l}\text { Kewajban pelaporan berlaku, } \\
\text { karena Malaysia merupakan } \\
\text { negara solk-assossment. }\end{array}$ \\
\hline 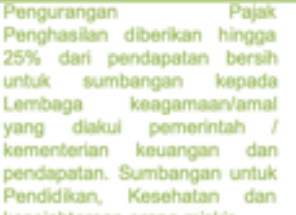 & 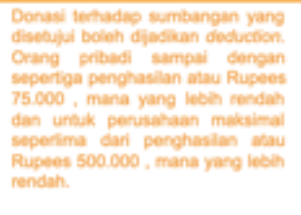 & 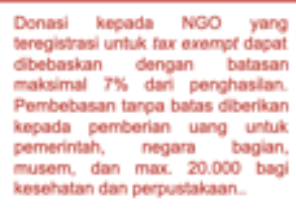 \\
\hline
\end{tabular}

Sumber: Elaborasi Peneliti 